\title{
Lexical Inferencing in Listening: Depth of Vocabulary Knowledge and Listening Proficiency
}

\author{
Elham Mohammadi Foomani \\ Dept. of Foreign Languages \& Literatures, University of Tehran \\ PO Box 82089168, Tehran, Iran \\ E-mail: foomanielham@alumni.ut.ac.ir
}

Received: July 17, 2015 Accepted: July 30, 2015 Published: July 31, 2015

doi:10.5296/ijele.v3i2.8081 URL: http://dx.doi.org/10.5296/ijele.v3i2.8081

\begin{abstract}
Lexical inferencing as an efficient strategy to deal with unfamiliar words is suggested to be the most commonly used strategy among students, thus it has attracted much attention in the comprehension literature. While literature abounds with inferencing studies in reading, few studies have delved into the processes involved in listening. This study sought to investigate the role of depth of vocabulary knowledge (DVK) in lexical inferencing success and determine the relationship between students' DVK and listening proficiency. To this end, 56 upper-intermediate TOEFL applicants from 2 language institutes in Iran participated in this study. The participants were assigned to three levels of High- Mid- and Low-proficiency and in a consequent session were required to take the 40-item DVKT (Depth of Vocabulary Knowledge Test). In the final step the students sat for the lexical inferencing task and were required to identify the meaning of 17 unfamiliar words in 8 listening excerpts. The results indicated that DVK was a determining factor in lexical inferencing success, and that there was a positive relationship between students' DVK and their listening proficiency.
\end{abstract}

Keywords: lexical inferencing, strategy, listening, DVK 


\section{Introduction}

Vocabulary knowledge underlies a number of language abilities such as L2 proficiency and reading (Grabe \& Stoller, 2002; Schmitt, Jiang \& Grabe, 2011). It is believed that vocabulary can be regarded as an accurate predictor of a text's difficulty (Nation \& Coady, 1988). It is estimated that a 98\% coverage of words in needed for comprehension of texts (Schmitt et al., 2011). He believes that in order to function in English, vocabulary as large as 8000-9000 word families is needed for an adequate reading, and as many as 5000-7000 families for functioning in oral discourse (Schmitt, 2008). This is while Laufer (2000) reports that the real size of vocabulary for high-school/university students of English was around 1000 to 4000 . Therefore acquiring a vocabulary size of 7000 to 8000 families for coverage of $98-99 \%$ of the text sounds an unreasonable, unattainable task. This indicates a need for strategy use since despite the size of the vocabulary knowledge there are always some vocabularies in every text that are unfamiliar. Different strategies are associated with different skills and subskills. Chamot and Kupper (1989) associate strategies of elaboration and inferring with listening comprehension. Making guesses and inferencing are both handy for L2 listening and reading. Haastrup (1991) defines lexical inferencing as "making informed guesses as to the meaning of a word in light of all available linguistic cues in combination with the learners' general knowledge of the world, her awareness of context and her relevant linguistic knowledge" (p. 197). Various studies have indicated the vital role of guessing and inferencing and the learner's tendency to utilize the strategy (Fraser, 1999; Paribakht \& Wesche, 1999) One of the prevailing cognitive processes in reading is claimed to be inferencing (Nassaji, 2004). He concludes that "lexical inferencing has been found to be the mostly widely used by L2 learners" (p. 647). Inferencing is an adequate strategy but as stated by Cai and Lee (2010a): "While much research has been done on unfamiliar word processing in reading comprehension, empirical studies specifically investigating this issue in listening comprehension are still limited. Not much is known about how L2 learners process unfamiliar words in listening comprehension" (p. 126).

\section{Review of the Related Literature}

\subsection{Lexical Inferencing}

Goh (2000) reported that half of students' comprehension problems could be attributed to word recognition and attention failure in perceptual processing of materials. Kurita (2012) regards Vocabulary knowledge as a critical predictor of listening comprehension, he notes that encountering unknown vocabularies might cause listening anxiety and may inhibit deep comprehension. Lexical inferencing as an efficient strategy can be used to deal with unknown words in texts and in fact based on the literature; it is one of the mostly used strategies among EFL learners. Guessing and inferring are two handy strategies for L2 comprehension for students. Fraser's (1999) study, for instance, suggested that $58 \%$ of the total strategy use was dedicated to inferencing and Paribakht and Wesche (1999) indicated 80\% use of inferencing strategy among students. Also in his study, Nassaji (2003) concluded that "lexical inferencing has been found to be the mostly widely used by L2 learners" (p. 647).

While there are researches that investigated strategy use focusing on reading or writing skills 
(Bengeleil \& Paribakht, 2004; Huckin \& Bloch, 1993; Kaivanpanah \& Alavi, 2008; Kern, 1989; Lee \& Wolf, 1997; Parel, 2004; Paribakht \& Wesche, 1999; Riazi \& Babaei, 2008), studies that have investigated the issue in listening mode are quite rare (Cai \& Lee, 2010b; Cai \& Wu, 2007). Little is known of lexical inferencing in listening and the factors influencing inferencing success in an Iranian context. Cai and Lee (2010b) suggested that contextual clues and language proficiency levels influenced unfamiliar word processing in listening. Lee and Cai (2010) reported the same results and demonstrated that language proficiency actually affects students' use of strategies.

\subsection{Factors Influencing Inferencing Success}

Different factors have been reported to have influences on lexical inferencing of students. Paribakht (2005) categorizes these factors into two broad categories of contextual and learner-related factors. Based on the previous studies learner-related factors include factors such as learners' previous L2 learning experience (Fraser, 1999; Paribakht \& Wesche, 1999,2006), learner's native language (Paribakht, 2005), learners' attention to text details (Frantzen, 2003), learners' depth of vocabulary knowledge (Nassaji, 2003, 2004; Qian, 1998, 2002, 2005) learners' sight vocabulary, their background knowledge and topic familiarity (Pulido, 2004, 2007; Atef-Vahid, Maftoon \& Zahedi, 2013).

\subsection{Depth of Vocabulary Knowledge}

Various aspects have been associated with word knowledge (Nation, 1990, p31). Qian and Schedl (2004) regard vocabulary as a multidimensional knowledge consisting of depth and breadth. Some researchers such as Schmitt and Meara (1997) and Wesche and Paribakht (1996) noted that to consider merely the breadth of vocabulary knowledge is not of much value since it ignores the more important aspect of word knowledge and that words can be known for a greater or lesser extent. While breadth of vocabulary knowledge refers to size of vocabulary a person knows at a particular level of competence (Nation, 2001), depth of vocabulary knowledge refers to components such as pronunciation, spelling, meaning, register, frequency, and morphological, syntactic, and collocational properties.

It has been acknowledged in recent years that vocabulary is an efficient predictor of students' language performance (Milton et al., 2010; Schoonen, 2010; Stahr, 2008). This is while most researches focus on the size (breadth) of vocabulary knowledge and ignore the more important aspect or depth of vocabulary knowledge. The few studies focusing on depth of vocabulary knowledge and language performance are in the realm of reading (Stahr, 2008). It is reported in the literature that Depth of vocabulary knowledge deeply influences reading comprehension (Akbarian, 2010; Farvardin \& Koosha, 2011; Mehrpour, Razmjoo \& Kian, 2011; Qian, 1998; Rashidi \& Khosravi, 2010). Little evidence exists as to the role of depth of vocabulary knowledge on listening performance of the students. Stahr (2008) and Wang (2015) reported a positive relationship between depth of vocabulary knowledge and listening performance.

On the other hand the role of depth of vocabulary knowledge in lexical inferencing success while reading has been investigated widely and literature supports the positive impact of depth of vocabulary knowledge on comprehension (Ehsanzadeh, 2012; Farahani, 2006; Kaivanpanah 
\& Soltani-Moghadam; Kaivanpanah \& Zandi, 2009). This is while the role of depth of vocabulary on lexical inferencing in listening and the possible relationship between listening proficiency and depth of vocabulary has not yet been investigated.

\section{The Present Study}

While lexical inferencing seems to be a crucial strategy to deal with unknown words and increase comprehension, and taking into account the vitality of listening comprehension, in an Iranian context lexical inferencing in listening has been left untouched. With regard to the fact that vocabulary is a determining factor in comprehension, and since depth of vocabulary is a factor that might affect students' lexical inferencing success, this study aims to investigate the role of depth of vocabulary knowledge. Having this introduction in mind, the following research questions will be addressed in this study:

1. Is there any relationship between Iranian EFL learners' depth of vocabulary knowledge and their lexical inferencing success?

2. Is there a relationship between students' depth of vocabulary knowledge and their listening proficiency?

\section{Methodology}

\subsection{Participants}

A total of 56 male and female students, from two language institutions in Iran, UTLC in Tehran and Zaban-Sara in Zanjan, participated in this study. The students were attending the TOEFL preparation courses and according to the institute placement test they were all upper-intermediate students with regard to their proficiency. The rationale for choosing this proficiency level was to make sure that the students were proficient enough to make inferences. The participants shared their first language as well as their cultural and societal backgrounds. They were university students in different fields both in state and open universities. Their age ranged from 18 to 35 . Worthy of note is that some of them were excluded from the analysis, in the cases that they could not complete all the steps of the study; so having gone through all the steps of the study left us with 56 participants (out of 90) for analysis.

\subsection{Instruments}

\subsubsection{TOEFL-PBT Listening Test}

The listening section of a TOEFL-PBT taken from a TOEFL-PBT kit (published in 2005) was used to measure the subjects' listening proficiency. The participants were told about the purpose of the study and what they were expected to do in the first 5 minutes and sat for the test for 35 minutes and answered the multiple choice items following the listening excerpts. The total score was 50, based on which the participants were assigned into Low- High and Mid-proficiency levels.

\subsubsection{DVKT}

For assessing the participants' depth of vocabulary knowledge the students were required to 
take the depth of vocabulary knowledge test (DVKT), developed by Qian and Schedl (2004). This test consists of two parts the first of which is related to polysemy and synonymy, and the second to collocations. The participants were asked to choose an alternative and write it in the answer sheet they were provided with. The test consisted of 40 items, for each of them four correct choices were to be selected, therefore the total score was 160 .

\subsubsection{Lexical Inferencing Task}

The students were provided with some listening excerpts which were chosen from a TOEFL-PBT listening subset, each containing 1 to 4 unfamiliar words for inferencing purposes. The listening materials consisted of 4 conversations and 2 lectures as with the TOEFL-PBT listening section. The 8 texts ranged from short conversations of 20 words in 6 seconds of listening and long conversations of around 30 seconds to lectures of 1.5 minutes length. In order to guarantee the appropriateness (being comprehensible with regard to the students' level) of the listening, the excerpts were selected from a TOEFL-PBT test. A panel of 4 teachers checked the appropriateness of the excerpts and the inferenciblity of the words. In order to check for the practical issues, a pilot test was conducted with 10 participants similar to the population of the main study in terms of proficiency to check for the comprehensibility of the texts. Haastrup's (1991) set of criteria were taken into account in the next step. Only content words were included and the words instigated the use of different knowledge sources ("Chorus", "subsidized", "drilling" for example represented the use of interlingual cues. "unbeknownst" and "reenactment" were words to be inferred using only intralingual cues) and included diverse comprehension processes (for example the use of affixes; biosphere", "reenactment", "repellent").

In a final step Nation's (1985) criterion was taken into account: that in order to infer word meanings a high percentage (95\%) of the words in the co-text should be familiar to students. To keep up with this criterion and as the teachers suggested the word "torso" was omitted and the percentage of unfamiliar text was counted with the following formula: All the words unknown to the students divided by all the words of the texts multiplied by 100 . For all the texts the unfamiliarity percent was found to be ranging from 2 to 5 which is acceptable and agrees with the $95 \%$ proposed by Nation (2006). Also to make sure that there was a 95 to $98 \%$ of understanding, the students were allowed to ask for the meaning of unknown words other than those to be inferred. Finally all these processes left the study with 17 words in 8 listening excerpts the appropriateness of which was previously affirmed by the pilot study and the 2 teachers of the same institutes.

\subsubsection{Vocabulary Knowledge Scale}

To ensure that none of the participants had any previous knowledge of the vocabularies, the Wesche and Paribakht's (1996) vocabulary knowledge scale was used. The students were asked to indicate whether they knew a word and choose one of the items of the scale.

\subsection{Procedure}

The participants of the study were all upper-intermediate and advanced learners of English taking different TOEFL courses at three levels. Since there was no possibility of a test 
administered at the same time with all the participants, and the participants were in different classes and at two different institutes in Tehran and in Zanjan, the tests were held in each class at different times. For each test of the study half the test-time was taken from the class time and the other half from the learners who accepted to stay the extra time in the class.

In order to answer the $2^{\text {nd }}$ research question, listening proficiency of the students had to be tested to categorize the students into three levels of High, Mid and Low proficiency and correlate the proficiency level with depth of vocabulary knowledge. In order to examine the listening proficiency of the students, a listening subset of TOEFL-PBT was utilized. The test was of three sections and 50 items which would take 35 minutes. Another 5 minutes at the beginning of the test was dedicated to explaining the test sections and procedures so that the students knew the aim of the test and got familiar with its' sections and therefore were more willing to cooperate. All in all this phase of the study lasted for 40 minutes.

In the next session and to examine the learners' depth of vocabulary knowledge the DVKT was distributed to the students, with 40 items and 35 minutes to answer the items. The first 5 minutes again was dedicated to spelling the test features and how the students were going to answer the items. Here, before the last phase of the study which was administering the lexical inferencing task, a pilot study with 10 participants with the same features as the participants of the study was conducted in order to check for the reliability of the task and for the consideration of possible flaws. Finally in the third and the last phase of the study, the lexical inferencing task was given to the students to examine their lexical inferencing success, in order to investigate the possible correlations.

\subsection{Data Collection}

All the students were required to take a TOEFL-PBT listening subset which consisted of 50 multiple choice items. The test took 40 minutes totally, with 35 minutes for the test and another 5 minutes of familiarizing the students with the purpose of the test and the process of the exam. The test was worth a point for each item which made 50 points totally, based on which the students were assigned to 3 levels of proficiency namely High Mid and Low. In the next step, the students were required to take the DVKT developed by Qian and Schedl (2004), which was regarded as a representative of students' depth of vocabulary knowledge. Next in another session the participants sat for the lexical inferencing task.

Before starting the task the students were informed of the purpose of the study and were given some overall information on what they were supposed to do with the data and how the task would be like. The unfamiliar vocabulary was played individually and to ensure that they did not have any previous knowledge of them they took the knowledge of the vocabulary scale developed by Wesche and Paribakht (1996). After indicating their knowledge of the vocabularies in the scale the papers were collected and then they listened to the conversations and the lectures and reported the meanings they had guessed in the answer sheet they were provided with before the task.

\subsubsection{Scoring}

The tests were scored. The TOEFL-PBT listening subset consisted of 50 items, assigning 
each item one point, thus the score the students obtained could range from zero to 50 based on which the participants were categorized into 3 groups of proficiency. In order to determine the DVKT results, the number of correct choices was counted; the test consisted of 40 items, each item had 8 alternatives out of which 4 correct choices were to be selected. Therefore the DVKT could score 160 maximally. To check the third study instrument namely the inferencing task, the answer sheets were corrected by the researcher and another teacher separately. The process of scoring the success or failure of the inferencing task included 3 steps of scoring separately, matching the two sets of scores and finally adjusting for the difference for a high percentage of agreement. Each item could have a value of 0 to 2 points depending on the degree of correctness according to Nassaji (2003)'s criteria, semantically, syntactically and contextually appropriate responses were regarded as totally successful receiving 2 scores, semantically appropriate but syntactically deviant responses or the opposite were regarded as partially successful and received 1 point, responses that did not meet any of the conditions were totally wrong and received 0 . There were 17 target words in the lexical inferencing task thus the total score for the task ranged from 0 to 34 scores. After the scoring step the scores were matched and a 94 percent agreement resulted, disagreements were then discussed and then an agreement of 100 percent was achieved.

\section{Results}

\subsection{Students' Depth of Vocabulary Knowledge and their Lexical Inferencing Success}

A regression was performed to determine how much of the inferencing scores' variance is explained by the depth of vocabulary knowledge. The results appear in tables 1 and 2, the results indicate that the DVKT scores define 48 percent of the inferencing task success.

Table 1. Model fit

\begin{tabular}{|c|c|c|c|c|c|c|c|c|}
\hline \multirow[b]{2}{*}{$\mathrm{R}$} & \multirow[b]{2}{*}{ R Square } & \multirow{2}{*}{$\begin{array}{l}\text { Adjusted } \\
\text { R Square }\end{array}$} & \multirow{2}{*}{$\begin{array}{c}\text { Std. Error } \\
\text { of the } \\
\text { Estimate }\end{array}$} & \multicolumn{5}{|c|}{ Change Statistics } \\
\hline & & & & $\begin{array}{c}\text { R Square } \\
\text { Change }\end{array}$ & F Change & df1 & df 2 & $\begin{array}{c}\text { Sig. F } \\
\text { Change }\end{array}$ \\
\hline $.693 \mathrm{a}$ & 0.48 & 0.47 & 4.675 & 0.48 & 50.713 & 1 & 55 & 0.000 \\
\hline
\end{tabular}

b Dependent Variable: Inferencing Task

Table 2. ANOVA results for regression analysis

\begin{tabular}{cccccc}
\hline & Sum of Squares & df & Mean Square & F & Sig. \\
\hline Regression & 1108.429 & 1 & 1108.429 & & \\
Residual & 1202.132 & 55 & 21.857 & & 0.000 \\
Total & 2310.561 & 56 & & \\
& a Dependent Variable: Inferencing Task \\
& b Predictors: (Constant), DVKT & \\
\hline
\end{tabular}


The Sig. value as presented in table 4.6. is 0.00 which is much less than the 0.05 criterion and thus acceptable.

In the Table 3. the unstandardized coefficient for DVKT is 0.199 . In order to check its significance a t-test was conducted. The sig is 0.00 as shown in the table; therefore the DVKT affects lexical inferencing success of the students.

Table 3. Coefficientsa

\begin{tabular}{cccccc}
\hline \multicolumn{2}{c}{$\begin{array}{c}\text { Unstandardized } \\
\text { Coefficients }\end{array}$} & \multicolumn{2}{c}{ Standardized Coefficients } & T & Sig. \\
\cline { 1 - 4 } B & Std. Error & Beta & \\
\hline (Constant) & -6.262 & 2.605 & --- & -2.404 & 0.02 \\
\hline DVKT & 0.199 & 0.028 & 0.693 & 7.121 & 0.000 \\
\hline
\end{tabular}

a Dependent Variable: Inferencing Task

\subsection{Students' Depth of Vocabulary Knowledge and Their Listening Proficiency}

In order to investigate the relationship between students' depth of vocabulary knowledge and their listening proficiency, Pearson's correlation was used. Table 4 shows the result.

Table 4. Correlation between DVK and listening proficiency

\begin{tabular}{ccc}
\hline $\mathrm{N}$ & Correlation & Sig. \\
\hline 57 & 0.948 & 0.000
\end{tabular}

As indicated in Table 4, the sig is 0.00 ; therefore there is a significant positive relationship between students' depth of vocabulary and their listening proficiency.

\section{Discussion}

Lexical inferencing performance of Iranian EFL learners was investigated to determine if their DVK could predict their lexical inferencing performance. The results of the study indicate that the learners' DVK might be a determining factor in their lexical inferencing attempts, in a way that the students who obtained better scores in the DVK were more successful in generating correct inferences when encountered with the Target words. This result is in line with Nassaji's (2004) findings that the richness of learners' pre-existing semantic system significantly influences their lexical inferencing performance. It should be mentioned that the semantic richness is gained gradually and with improvements in learners' proficiency which also supports the finding as to the role of listening proficiency in inferencing. One justification for this finding can be that as Nassaji (2003) claims learners with deeper vocabulary knowledge are more successful in making use of the knowledge sources available and can efficiently make semantic networks through the text and thus make more correct guesses. This finding also highlights the importance of the role of lexical knowledge and how it can be helpful in the process of making semantic frameworks and 
achieving thorough understanding of the texts.

The results of the study also highlight the relationship between listening proficiency and depth of vocabulary. This finding is in line with previous research which emphasized the role of depth of vocabulary knowledge in skill performances (Milton et al., 2010; Schoonen, 2010) as well as in reading comprehension (Akbarian, 2010; Farvardin \& Koosha, 2011; Mehrpour, Razmjoo \& Kian, 2011; Qian, 1998; Rashidi \& Khosravi, 2010). The results also are in line with previous research pertaining to the role of vocabulary knowledge (Wang, 2015) and depth of vocabulary knowledge in particular (Stahr, 2008) in listening comprehension.

\section{Conclusions and Implications}

With regard to the fact that vocabulary is vital for language use and that lexical inferencing can be an efficient method for establishing students' focus on new vocabulary items and enter and reinforce lexical items into their semantic networks, studies on lexical inferencing as an strategy can be helpful in giving new insights as to the nature of the processes at hand. However in this study and in other similar studies it is reported that the students, even the proficient ones have difficulties making efficient use of them for generating plausible meanings for the unknown words. Therefore it is crucial that teachers familiarize students with lexical inferencing strategy. Since a considerable degree of input is received by the students through listening, extensive listening can probably serve as an efficient way for students to enhance their vocabulary knowledge. Especially for EFL leaners who do not have opportunities of target language input outside the classroom, listening and lexical inferencing as a medium can be of great help. Depth of vocabulary knowledge was found to have a determining impact on students' lexical inferencing success. Teachers should be on the alert to use different opportunities to increase students' depth of vocabulary knowledge and drive the focus away from breadth and towards depth of vocabulary knowledge. Another suggestion for teachers is to implement lexical inferencing exercises in the classroom, basically in the form of listening activities including some unfamiliar words which encourage students inference generation. In conducting lexical inferencing tasks, students' level should be taken into account. Care should be taken that the level of familiarity of the text be appropriate for the students. The text should be at least 95 percent comprehensible for students to be able to derive the meaning of the unknown words. Also it should be pointed that the teachers should emphasize that not all the unknown words encountered are to be inferred and as Field (2008) suggests: they should check their inferences with the upcoming new information. Regarding the crucial role of depth of vocabulary knowledge in listening proficiency, more emphasis should be asserted by teachers on lexical knowledge in the classrooms.

\section{Suggestions for Further Research}

This study was an attempt to shed some light on lexical inferencing as a strategy to deal with unknown words when listening. Similar studies can be carried out with more participants and with taking gender factor into account. With regard to the findings of the study and the complex nature of lexical inferencing, studies might be conducted to investigate the other factors that might influence lexical inferencing success of students. Different factors might 
affect lexical inferencing process and success of Iranian EFL students, such as reader-related factors as gender, proficiency level, and course of study or text factors, for example texts with different genres can be subject to further studies of lexical inferencing. Also further research can be conducted to investigate the vocabulary retention that might occur as a result of lexical inferencing tasks implemented into language classes. This study also investigated the role of students DVK on lexical inferencing success, other studies might be carried out to investigate the role of breadth of vocabulary knowledge on students' lexical inferencing. In other studies the role that breadth of vocabulary knowledge plays may be compared to the role of DVK and how they might happen to act differently for students with different proficiency levels.

\section{References}

Akbarian, I. (2010). The relationship between vocabulary size and depth for ESP/EAP learners. System, 38, 391- 401.

Atef-Vahid, S., Maftoon, P., \& Zahedi, K. (2013).Topic familiarity, passage sight vocabulary, and L2 lexical inferencing: An investigation in the Iranian EFL context. International Journal of Research Studies in Language Learning, 2(4), 79-99. http://dx.doi.org/10.5861/ijrs1l.2012.216

Bengeleil, N. F., \& Paribakht, T., S. (2004). L2 reading proficiency and lexical inferencing by university EFL learners. The Canadian Modern Language Review, 61(2), 225-249.

Cai, W., \& Lee, B., P., H. (2010a). Processing Unfamiliar Words: Strategies, Knowledge Sources, and the Relationship to Text and Word Comprehension. The Canadian Journal of Applied Linguistics, 15(1), 122-145.

Cai, W., \& Lee, B., P., H. (2010b). Investigating the Effect of Contextual Clues on the Processing of Unfamiliar Words in Second Language Listening Comprehension. Australian Review of Applied Linguistics, 33(2), 18.1-18.28.

Cai, W., \& Wu, Y. (2007); lexical inferencing in second language listening comprehension. Foreign Languages and Their Teaching, 7, 1-5.

Chamot, A. U., \& Kupper, L. (1989). Learning strategies in foreign language instruction. Foreign Language Annals, 22, 13-24.

Ehsanzadeh, S. J. (2012). Depth versus breadth of lexical repertoire: assessing their roles in EFL students' incidental vocabulary acquisition. TESL CANADA JOURNAL/REVUE TESL DU CANADA, 29(2), 24-41.

Farahani F. (2006). The relationship between depth of vocabulary knowledge and EFL learners' lexical inferencing strategy use and success. Unpublished Master's thesis. Shiraz Azad University.

Farvardin, M., \& Koosha, M., The Role of vocabulary knowledge in Iranian EFL students' reading comprehension performance: breadth or depth. Theory and Practice in Language Studies, 1(11), 1575-1580. http://dx.doi.org/10.4304/tpls.1.11.1575-1580 
Fraser, C. A. (1999). Lexical processing strategy use and vocabulary learning through reading. Studies in Second Language Acquisition, 21, 225-241.

Frantzen, D. (2003). Factors Affecting How Second Language Spanish Students Derive Meaning from Context. Modern Language Journal, 87(2), 168-199.

Goh C. (2000). A cognitive perspective on language learners' listening comprehension problems. System, 28(2000), 55-75.

Grabe, W. \& Stoller, F. (2002). Teaching and Researching Reading in L2. UK: Longman.

Haastrup, K. (1991). Lexical inferencing procedures or talking about words. Tubingen: Gunter Narr.

Huckin, T., \& Bloch, J. (1993). Strategies for inferring word-meanings in context: A cognitive model. In T. Huckin, M. Haynes, \& J. Coady (Eds.), Second language reading and vocabulary learning, 153-176. Norwood, NJ: Ablex.

Kaivanpanah S., \& Alavi, S., M. (2008) The role of linguistic knowledge in word-meaning inferencing. System, 36, 172-95.

Kaivanpanah, S., \& Soltani Moghaddam, M. (2012). Knowledge Sources in EFL Learners' Lexical Inferencing across Reading Proficiency Levels. RELC Journal, 43(9), 373-391. http://dx.doi.org/10.1177/0033688212469219

Kaivanpanah, S., \& Zandi, H. (2009). The Role of Depth of Vocabulary Knowledge in Reading Comprehension in EFL Contexts. Journal of Applied Sciences, 9, 698-706.

Kern, R. G. (1989). Second Language Reading Strategy Instruction: Its Effects on Comprehension and Word Inference Ability. The Modern Language Journal, 73(2), 135-149.

Kurita, T. (2012). Issues in second language listening comprehension and the pedagogical implications. Accents Asia, 5(1), 30-44.

Laufer, B. (2000). Task effect on instructed vocabulary learning: The hypothesis of “involvement." Selected papers from AILA'99 Tokyo (pp. 47-62). Tokyo:Waseda University Press.

Lee, B. P, H., \& Cai, W. (2010). The Effects of Language Proficiency on Unfamiliar Word Processing in listening Comprehension. Hong Kong Journal of Applied Linguistics, 12(2), $61-82$.

Lee, J., \& Wolf, D. (1997). A quantitative and qualitative analysis of word-meaning inferencing strategies of L1 and L2 readers. Spanish Applied Linguistics, 1, 24-64.

Mehrpour S., Razmjoo S. A., \& Kian P. (2011). The Relationship between Depth and Breadth of Vocabulary Knowledge and Reading Comprehension among Iranian EFL Learners. Journal of English Language Teaching and Learning, 222, 97-127.

Milton J., Wade, J., \& Hopkins, N. (2010). Aural word recognition and oral competence in a foreign language. In R. Chacón-Beltrán, C. Abello-Contesse, \& M. Torreblanca-López (Eds.), 
Further insights into non-native vocabulary teaching and learning (pp. 83-98). Bristol: Multilingual Matters.

Nassaji, H. (2004). The relationship between depth of vocabulary knowledge and L2 learners' lexical inferencing strategy use and success, Canadian Modern Language Review, 61(1), 107-134.

Nassaji, H. (2003). L2 vocabulary learning from context: strategies, knowledge sources, and their relationship with success in L2 lexical inferencing. TESOL Quarterly, 37(4), 645-667. http://dx.doi.org/10.2307/3588216

Nation, I. S. P. (2006). How large a vocabulary is needed for reading and listening? The Canadian Modern Language Review, 63(1), 59-82.

Nation, I. S. P. (2001). Learning vocabulary in another language. Cambridge: Cambridge University Press.

Nation, I. S. P. (1990). Teaching and learning vocabulary. New York: Newberry House.

Nation, I. S. P., \& Coady, J. (1988). Vocabulary and Reading. In R. Carter \& M. McCarthy (Eds.), Vocabulary and language teaching (pp. 97-110). London: Longman.

Parel, R. (2004). The impact of lexical inferencing strategies on second language reading proficiency. Reading and Writing: An Interdisciplinary Journal, 17, 847-873.

Paribakht, S. (2005). The Influence of First Language Lexicalization on Second Language Lexical Inferencing: A Study of Farsi-Speaking Learners of English as a Foreign Language. Language Learning, 55(4), 701-748.

Paribakht, T. S., \& Wesche, M. (2006). Lexical inferencing in L1 and L2: Implications for vocabulary instruction and learning at advanced levels. In H. Byrnes, H. Weger-Guntharp \& K. Sprang (Eds.), Educating for advanced foreign language capacities: Constructs, curriculum, instruction, assessment (pp. 118-135). Washington, DC: Georgetown University Press.

Paribakht, T. S., \& Wesche, M. (1999). Reading and Incidental L2 Vocabulary Acquisition: An Introspective Study of Lexical Inferencing. Studies in Second Language Acquisition, 21(2), 195-224. http://dx.doi.org/10.1017/S027226319900203X

Pulido, D. (2007). The Effects of Topic Familiarity and Passage Sight Vocabulary on L2 Lexical Inferencing and Retention through Reading. Applied Linguistics, 28, 66-86. http://dx.doi.org/10.1093/applin/aml049

Pulido, D. (2004). The effect of cultural familiarity on incidental vocabulary acquisition through reading. The Reading Matrix, 4, 20-53.

Qian, D. D. (2005). Demystifying lexical inferencing: The role of aspects of vocabulary knowledge. TESL Canada Journal, 22(2), 34-54.

Qian, D. D. (2002). Investigating the relationship between vocabulary knowledge and academic reading performance: An assessment perspective. Language Learning, 52, 513-536. 
Qian, D. D. (1998). Depth of vocabulary knowledge: Assessing its role in adults' reading Comprehension in English as a second language. Unpublished Doctoral Thesis. University of Toronto.

Qian, D. D., \& Schedl, M. (2004). Evaluation of an in-depth vocabulary knowledge measure for assessing reading performance. Language Testing, 21, 28.

Rashidi N., \& Khosravi N. (2010) Assessing the role of depth and breadth of vocabulary knowledge in reading comprehension of Iranian EFL learners. Journal of Pan-Pacific Association of Applied Linguistics; 14(1), 81-108.

Riazi, A., \& Babaei, N. (2008). Iranian EFL female students' lexical inferencing and its relationship to theirL2proficiency and reading skill. The Reading Matrix, 8, 186-195.

Schmitt, N. (2008). Instructed second language vocabulary learning. Language Teaching Research, 12, 329-363.

Schmitt, N., Jiang, X., \& Grabe, W. (2011). The Percentage of Words Known in a Text and Reading Comprehension. The Modern Language Journal, 95, 26-43. http://dx.doi.org/10.1111/j.1540-4781.2011.01146.x

Schmitt, N., \& Meara, P. (1997). Researching vocabulary through word knowledge framework: Word associations and verbal suffixes. Studies in Second Language Acquisition, $19,17-36$.

Schoonen, R. (2010). The development of lexical proficiency knowledge and skill. Paper presented at the Copenhagen Symposium on Approaches to the Lexicon, Copenhagen Business School on 8-10 December 2010. Accessed at https://conference.cbs.dk/index.php/ lexicon/ lexicon/schedConf/ presentations on 03.03.2011.

Stæhr, L. S. (2008). Vocabulary size and the skills of listening, reading and writing. Language Learning Journal, 36(2), 139-152.

Wesche, M., \& Paribakht, T. S. (1996). Assessing second language vocabulary knowledge: Depth versus breadth. The Canadian Modern Language Review, 53(1), 13-39.

\section{Copyright Disclaimer}

Copyright for this article is retained by the author(s), with first publication rights granted to the journal.

This is an open-access article distributed under the terms and conditions of the Creative Commons Attribution license (http://creativecommons.org/licenses/by/3.0/). 